\title{
I4
}

PAMELA K. GILBERT

\section{Sensation fiction and the medical context}

\author{
[T] he pleasure which we may conceive taken by the children of the \\ coming time, in the analysis of physical corruption, guides, into fields \\ more dangerous and desolate, the expatiation of an imaginative \\ literature: and that the reactions of moral disease upon itself ... have \\ become the most valued material of modern fiction, and the most eagerly \\ discussed texts of modern philosophy. ${ }^{\mathrm{I}}$
}

John Ruskin, that temperamental commentator on the arts of his time, was displeased with the general tendency of mid nineteenth-century literature to focus on non-ideal physical and mental states. Within this trend, sensation fiction was a genre particularly connected to current understandings of physiology and medicine. Its madwomen and nerve-wracked men existed in a cultural context of acute interest in the body's relation to the mind and soul, in which anti-social actions earlier attributed to evil and sin began to be explained in terms of degenerate constitutions and maniacal obsessions. This chapter will outline some of the background of medical history in the period, and its specific resonance in sensation fiction, including the presence of medical men as heroes and villains. A detailed reading of Wilkie Collins's Armadale (I 866) offers an example of the centrality of such themes to a novel that, at first glance, might seem less clearly tied to medical history than many other novels that have been so read.

\section{Medical history and fictional form}

The mid-Victorian period saw the rise of the modern medical profession. In the early part of the century, there was a dramatic increase in the production of medical knowledge, bringing a substantial break from earlier models of medicine dating back at least to the Renaissance. The advent of morbid pathology revolutionised surgery, as did the development of anaesthesia in the mid-century. New instruments and optics expanded the range of physiological investigation in living tissue. Statistical technologies of health demographics, such as morbidity and mortality statistics in the public health arena, and risk tables in the life assurance (insurance) industry shifted interest from I 82 
the individual sufferer to the broader population. New positivist approaches to medical evidence based on careful clinical examination became the standard for medical practice, and the old ideal of a doctor who interviewed a patient at length and knew him or her well as an individual was supplanted by an understanding of the clinician as an expert who relied on vision and nonverbal cues to interpret the condition of the patient, of which the sufferer might not even be aware, and was certainly incompetent to describe accurately. The patient as a unique subject was replaced by the model of the patient as a standardised bearer of constitutional and disease characteristics which were read as more important and telling than older notions of 'character'.

The novel, and, more specifically, the narrative mode of realism appropriates many of the techniques of the clinical medical gaze of this period: the focus on detailed and apparently objective description of minute but meaningful signs that must be interpreted by an expert (the author, and by flattering extension, the reader), careful cataloguing of physiological reactions (blushes, pallor, faintness), and a focus on the normative and everyday flawed, middle-class protagonist, rather than extreme or unusual situations and the heroic or villainous (often aristocratic) characters that marked the gothic or the romance. The quote by Ruskin with which this chapter begins refers not to sensation fiction by Braddon or Collins, but to the work of Dickens and Eliot. Literary critic and medical historian Lawrence Rothfield argues that the British and French nineteenth-century novel demonstrates that medicine and narrative realism take up 'similar strategies, construct similar kinds of subjects, [and] exert similar kinds of authority': novelists adopt not only 'a stock of characters but a set of quasi-artistic techniques, including, for example, a specifically symptomological semiology', as characters are embodied with particular pathologies and constitutions. ${ }^{2}$ Realism's penchant for both detailed description and 'round' characters with complex interiorities, as well as fiction's preoccupation with the temporal and causal progress of events, means that the medical case study both models and mirrors the novel. In terms of literary history itself, the style and form of the novel seem to break from the romance's focus on the marvellous and unique; instead, it again shares some of the qualities of the case study, and something of the same purpose: through the narration of a singular but typical story, it seeks to reveal a larger truth applicable to everyday life.

Sensation novels at first glance might seem to repudiate this realistic mode of narration and offer a return to the gothic, with its emphasis on the unique and unrepeatable. Improbable coincidences, unusual situations and extraordinary emotional challenges abound. Instead of confronting the typical and quotidian, characters are thrust into extreme situations - and come up with 
equally extreme responses. On second look, however, sensation novels are deeply indebted to the realist tradition. The characters tend to be ordinary middle- to upper-class folk. Stories are set in the present or recent past, and in familiar locations. Their struggles have to do with ordinary Victorian challenges and the typical stuff of the novel - debt, bankruptcy, identity and the legitimacy of marriages, children and heirs. All of these themes relate to the larger question that critic Raymond Williams famously identified as central to the mid-century novel: the elaboration of a knowable community, responding to readers' desire to feel that a large group of people could be fully known and understood in relation to each other in the wake of the disorienting social changes wrought by the Industrial Revolution. ${ }^{3}$ Sensation characters might best be said to experience realist challenges at an accelerated rate: whereas the realist protagonist has a detailed response to one or two of these conflict themes, sensation characters struggle with all of them in rapid succession. Their lives or case histories seem to be intensified and 'speeded up'.

The very notion of sensation itself is a physiological one, and its understanding by the critics and readers of its day was grounded in popular understandings of medicine and physiological psychology. As Henry Mansel disapprovingly said in I863, sensation fiction 'preaches to the nerves'. Many reviewers voiced the concern that the (usually female) reader of sensation was experiencing - and would then become addicted to seeking - a physiological 'thrill' that bypassed her rational mind and therefore her ability to evaluate and respond morally to the text. 'Good' literature caused the reader to think carefully, sympathise with realistic responses to situations and make careful judgements. It was nourishing 'food' for the mind, rather than an inappropriately stimulating 'dram or ... dose'. ${ }^{4}$ Sensation fiction was believed to develop a vitiated taste for ever more intense physiological stimulation.

The fiction itself focuses on physiology as well, alternately adopting a clinical view and challenging it for its materialist limitations. If the sensation novel is seen as acting upon the nerves, it is also preoccupied with the actions of other agents on the organism. Literary scholar Nicholas Daly notes that sensation thematised modernity through the actions of machines and modernity's reliance on new experiences of speed and shock associated with railways and telegraphs. (Likewise, sensation fiction was meant to be consumed - often by commuters on those railways - speedily, rather than slowly in a book-lined study.) Lady Audley is able to set her schemes in motion because she can run up to London quickly by rail and hardly be missed. Daly suggests that sensation novels provided a kind of 'temporal training' to inure people to the overstimulation of modern life. ${ }^{5}$ Both plot and pace were attuned to modern experience of temporality: sensation is, he notes 'a I 84 
Sensation fiction and the medical context

punctual form, depending on accurate time-keeping and scrupulous attention to the calendar'. ${ }^{6}$ Sensation fiction, then, contextualised human actions in an increasingly precise and mechanistic universe.

\section{Medical history and fictional content}

Some novels in the period depend for their principal interest on a particular physical condition: Collins's Poor Miss Finch (I 872) relies heavily on detailed discussions of the medical condition of the blind heroine and the psychological issues resulting therefrom, as well as the secondary but rather more spectacular silver nitrate treatment that unfortunately turns her fiancé a permanent, unattractive blue. Madness, hereditary and otherwise, features as a significant plot point for novels throughout the period. However, it is more usual for the medical condition of the characters simply to underlie their motivations and reactions, rather than to drive the plot directly. The sensation genre's interest in extreme medical and mental states connects with the period's interest in evolution, degeneration, barbarism and the Other. Inherited disease - madness or the kind of degeneration associated with 'vice' - which in the I 890 s come to be more directly articulated as infectious venereal disease and especially syphilis - in the I 860 s is associated with similar but vaguer symptoms (paralysis, exhaustion, idiocy) which can be inherited but is rarely presented as infectious. The loss of 'vitality' over the generations from a 'vicious' parent or ancestor thus refers to ideas of degeneration. But geography or racial otherness can also carry the burden of this significance. In Collins especially, foreign characters are the bearers of dangerous physical states, and this is particularly true of mixed-race characters such as Ozias Midwinter in Armadale or Ezra Jennings in The Moonstone (I 868).

While the form of the sensation novel evoked nervous stimulation and the threat of madness and addiction, the content of the sensation novel thematised the dangers of nervous disease. Physicians believed that the overstimulated nerve would progressively fail to respond to the same level of stimulus, thus requiring a stronger stimulus to achieve the same effect, until eventually the organism would collapse under the strain. The hermeneutic logic of the sensation form is obsessional: although one constantly discovers something surprising, the climax of ultimate discovery and closure in each case is deferred, demanding that the next revelation will be even more surprising. Obsession itself is structurally similar to addiction: both involve a craving that cannot be satisfied and indeed, that is only increased by being fed. Sensation fiction is particularly marked by its use of 'monomania', the Victorian term for obsession, as a theme, and this fascination dominates Dickens's fiction in the $\mathrm{x} 860$ s as well. 
The connection between femaleness and madness has been often remarked by Victorian scholars, and has been understood to be foundational to the gender politics of the period since Elaine Showalter's groundbreaking study of hysteria, The Female Malady (I985). The term 'hysteria' refers to the womb, and women were thought to be particularly vulnerable to insanity due to their physiologies. Their reproductive systems were thought to be so delicately balanced that even the healthy woman was always on the verge of mental dysfunction. That said, the period also sees an exploration of male hysteria, addiction and obsession. In both sensation and realist novels, men succumb to the temptations of gambling and market speculation in terms redolent of the period's understanding of addiction. Characters are addicted to alcohol, opium and its derivatives, gambling and, of course, sensation novels. None of these things, it turns out, are good for the nerves.

Braddon's Robert Audley fears being a monomaniac; Reade's Dr Wycherly simply is one; and from Collins's hypochondriacal Mr Fairlie of The Woman in White (I 859-60) to his nervous surgeon Dr Ovid and the sinister brain disease specialist Dr Benjulia in Heart and Science (I883) (who ultimately commits suicide, having become nervous himself), the insane male is the more sensational secret of many of these novels. After all, it was practically normal for a woman to be a little unbalanced, but the madman is a spectacle of horror as well as pity. More frighteningly, the madman (especially the monomaniac) seems to outsiders to function normally long after he is in fact quite ill. Braddon explores religious mania in her eponymous evangelical character Joshua Haggard, and of course Dickens's Eugene Wrayburn and Bradley Headstone in Our Mutual Friend (I 865) are both obsessive stalkers, though Headstone is the more obviously mad in Dickens's culture's sense of the term, as he stalks another man with murderous intent, rather than a woman with amorous purposes. (His madness is also distinctly somatised, causing him to have frequent nosebleeds.) Miserrimus Dexter in Collins's The Law and the Lady (I 875), one of the genre's many disabled characters, is burdened both with an absence of legs and an excess of nervous susceptibility, and is both mad and paralysed when he dies by the end of the novel.

\section{Medical heroes and villains: the surgeon and the mad-doctor}

After the clergyman, or minister of other denominations than the Church, who stands in such favour - and we are not at all jealous - with the real head of the family as the family doctor? .... Therefore, you have a power, an influence with men, and women too, in the middle ranks of life which none of us possess in the same degree. ${ }^{7}$ 
Given the importance of medicine in the Victorian novel, it is not surprising that medical professionals often feature as characters themselves, often as commentators who serve purposes of exposition in relating the condition of the main characters. The medical hero rose to prominence in the mid-century and was as frequently featured in sensation novels as his alter-ego, the lawyer (another rational middle-class professional). By the I 860s, doctors are everywhere in the fiction, but their uncanny ability to read symptoms and unearth secrets, as well as their drive to knowledge for its own sake, begins to have a darker side. In these novels, the legitimate doctor - often a surgeon - is akin to the novelist: a humane observer gifted with extraordinary perceptive abilities. The mad-doctor, however, may be mistaken in diagnosis, and even when he is legitimate and correct in his diagnosis, he is likely to suffer from a lack of humanity. The doctor, especially the doctor-scientist, becomes a frightening figure whose ability to sympathise with patients decreases as his brilliance increases: the doctor himself comes to have a god-complex, and if he is not mad in the strict sense, the latter-day Victor Frankenstein certainly becomes bad and dangerous to know.

Tabitha Sparks, in her recent study of the figure of the doctor in the Victorian novel, points out that as medical authority gained ground, the claim of the novelistic art to clarify the truth of the human condition waned, and fiction 'gradually loses the authority that medicine and science were claiming as the medical profession worked to locate the knowledge of human subjectivity in physiology, ${ }^{8}$ but the novels she studies 'agree that the doctor's authority comes at the cost of his isolation from society and morality, exactly the ruling domains of the marriage-plot novel ... Fictional doctors increasingly become lonely bachelors or callous experimentalists.' ${ }^{9}$ Several scholars have used Eliot's Middlemarch (I 872) as an exemplar of narrative as a clinical case study, with the added bonus that it includes a protagonist who is himself a scientifically minded surgeon, up on the latest French techniques. But as Peter Logan has pointed out, Eliot also wryly points up the blindness of certain kinds of scientific attitudes, and Lydgate's noble ambitions are thwarted. ${ }^{\text {IO }}$ Generally, however, these surgeon-characters are heroic, such as the doctors in Dickens's Little Dorrit ( I $855-7$ ) and Bleak House ( $1852-3$ ), or in Charles Kingsley's Two Years Ago (I 857 ). In Collin's Man and Wife, a surgeon, observing the physically splendid athlete Geoffrey, tells him he is in broken health. All observers around Geoffrey, and he himself, are incredulous: he is a prize-winning runner, oarsman and fighter. The surgeon alone is able to see that Geoffrey has dangerously depleted his strength, simply by observing his face at a distance. ${ }^{\mathrm{II}}$

In short, the medical professional is able to read the inner truth of characters, even without a medical examination, and through his authority, we 
understand a reality that the other characters cannot accept because they cannot see what the surgeon perceives, even though - or especially because they are observing Geoffrey in the same moment: 'The man who first declared that "seeing" was "believing" laid his finger (whether he knew it himself or not) on one of the fundamental follies of humanity. The easiest of all evidence to receive is ... the judgment of the eye' (219). The surgeon, of course, also relies on the judgement of the eye - however, he is gifted with the clinical gaze detailed by Foucault: a gaze which, though relying initially on visual inspection, sees more than the normal eye. It is important that the surgeon uses no instruments or tactile examination to perceive this truth. Because his gaze is uniquely trained, he can determine - with no more evidence available to him than to all the other characters - the truth that is invisible to them. In reading past the apparent truth of the individual to expose the universals of signs of disease, the doctor himself also in some sense transcends individuality, and is thus aligned with the novelist's ability to take in the whole of human experience.

The mid-century mad-doctor was a more ambivalent figure than the surgeon - perhaps in part because a surgeon rarely confined his patients (though he might well inadvertently kill them). Dr Francis Ainstie, in a plea for a more coherent system of medical expert testimony, observes that 'The practice of signing certificates for the committal of patients to houses of restraint is a very important matter ... because it has been made the ground of all kinds of suspicion against the candour and honesty of medical practitioners. The public has a chronic quarrel with "maddoctors", as the pages of many a sensation novel will testify. ${ }^{\mathrm{I2}}$ And indeed, popular culture in the r 860 s took up the theme of wrongful internment in madhouses with enthusiasm, as Charles Reade's Hard Cash (I 863) dramatises. The protagonist Alfred Hardie is wrongfully committed by his father, who seeks to cheat him of his inheritance. Alfred becomes friendly with Dr Wycherley, the superintendent, only to discover that Wycherly is himself a (mostly asymptomatic) monomaniac. High-profile cases and physicians caught the public's imagination. The celebrated novelist, Edward Bulwer Lytton, incarcerated his troublesome wife Rosina, who appealed to the law for release and was avenged upon him when she published her autobiography with a detailed description of her wrongful imprisonment. As Jill Matus points out, the scene of Lady Audley's imprisonment contains dialogue similar to that reported by Lady Rosina, well calculated to recall her description to the mind of the reader. ${ }^{13}$

Braddon's Dr Mosgrave, the mad-doctor in Lady Audley's Secret (I 862), is hardly jolly: 
Sensation fiction and the medical context

However powerful the science of medicine as wielded by Dr Alwyn Mosgrave, it had not been strong enough to put flesh upon his bones, or brightness into his face. He had a strangely expressionless, and yet strangely attentive countenance. He had the face of a man who had ... parted with his own individuality and his own passions at the very outset of his career. ${ }^{\text {I4 }}$

Dr Mosgrave is an ambiguous figure of authority. He aids Robert Audley, the reluctant 'hero' of the novel, but his own motives are questionable. Although he judges Lady Audley sane, and does not think she has committed murder, he is willing to permanently commit her quietly to a madhouse, where she will be, by his own statement, 'buried alive', on the strength of a twenty-minute interview:

If you were to dig a grave for her in the nearest churchyard and bury her alive in it, you could not more safely shut her from the world and all worldly associations. But as a physiologist and as an honest man, I believe you could do no better service to society than by doing this; for physiology is a lie if the woman I saw ten minutes ago is a woman to be trusted at large.

The ability to transcend individuality might easily slide into a repudiation of human subjectivity, and perhaps even a claim to a god-like right of judgement. Mosgrave judges Lady Audley 'as a physiologist' - that is, on the basis not of her actions, but of his expert observations of her body to determine actions of which he believes her capable - a standard which would hold in no court, and which equates her physiology to her soul. The 'expressionless' neutrality of scientific medicine, with its oracular ability to penetrate the secrets of the human heart, seemed almost supernatural in its abilities, but it could also seem inhuman and unsympathetic. Worse, doctors could be wrong.

In Collins's and Reade's novels mentioned above, the mad-doctors are not villains, but are simply deceived; still, their plots underscore the possibility that the mad-doctor is not a trustworthy diagnostician. As critic Peter Logan explains, it is a period in which definitions of insanity were rapidly changing and expanding. By the mid-century, celebrated alienist John Conolly offered a definition of insanity in a court case that was quite inclusive, considering even socially inappropriate behaviours as markers of insanity. In short, what had been considered mildly eccentric or even normal behaviours were increasingly identified as insane. The new category of 'moral insanity', including monomania or insanity regarding a 'discrete topic', meant that insanity might be diagnosed even in a person whose behaviours and physical health were apparently normal. ${ }^{15}$ The fiction of this period abounds with monomaniacs, and characters, who like Robert Audley, feared they might be becoming monomaniacal (though Dr Mosgrave, clearly having an opinion 
on Robert's mental health, keeps it to himself). And diagnoses of madness were certainly generally on the rise throughout the period. In I 824 , there were eight madhouses with an average of I I 6 beds each; by I 860 , there were $4 \mathrm{I}$ with an average of 386 - and the numbers continued to increase. ${ }^{\mathrm{I}}$ In I 88I, the noted physician J. Russell Reynolds rather drily observed that, although the existence of specialists in mental illness was undoubtedly 'a most direct advantage to the profession and the public' the drawback of such a speciality is that the "so-called "mad-doctor" fails, sometimes, to see anything from a sane point of view. The mens sana is a myth to him ... He may be right in regarding all people as somewhat mad, but he may be wrong in thinking that all men are so far mad as to require restraint.' ${ }^{17}$ The sensation novel explored the frightening possibility that anyone in the reader's environment might be mad. But the only thing more frightening - and likely - than being mad was being diagnosed and treated for it.

By the end of the century, the medical scientist emerges in fiction as distinctly suspicious. Collins's beastly vivisector and specialist in nervous and brain disease, Dr Benjulia, genuinely believes that he is serving humanity with the scientific torture of animals and experimentation, even when he employs it on human patients. Benjulia is a sinister figure - as monstrous in his 'gigantic' and foreign 'gypsy' person as in his inhuman cruelty. He is a doctor interested in the nerves, in 'brain diseases'. By the end of the century, the evil scientist-doctor - or the anti-feminist, oppressive doctor - appears in both such 'medical gothic' and New Woman novels; ${ }^{18}$ both are increasingly cast as threats to women. By I 896, Wells's Dr Moreau has been driven from Europe for his experiments, and becomes the cruel god of his own hapless little island in the South Seas until his creations finally rise against and kill him.

\section{Armadale}

Armadale offers a good example of many trends discussed in this chapter. First, the text is punctuated throughout by the appearance of doctors, who serve as independent observers and offer emotional and moral compass; however, they also represent the limits of materialist explanations of human experience and the frightening threat of the corrupt physician's access to the body and mind. The novel opens with a doctor in attendance on a dying man; the doctor represents the humane (and secular humanist) compassion that the other witness of the man's suffering, a deeply religious but uncharitable man, fails to demonstrate. Another kindly doctor at the centre of the novel uses medical frameworks to explain away a character's terrifying dream. A third humane surgeon met by chance on a journey warns the same character, I90 
Midwinter, that 'Your face tells me more than you think ... If you are ever tempted to overwork your brain, you will feel it sooner than most men. When you find your nerves playing you strange tricks, don't neglect the warning drop your pen.' Finally, Dr Downward, an abortionist turned mad-doctor (he founds an asylum for patients with 'shattered nerves'), is a criminal quack who joins forces with the unhappy villainness, Lydia Gwilt.

Dr Downward lacks the expressionlessness of Dr Mosgrave, but he is no less defined by his capacity for secretiveness: 'he was one of those carefully constructed physicians in whom the public - especially the female public implicitly trust ... His voice was soothing, his ways were deliberate, his smile was confidential.' ${ }^{19}$ The erstwhile abortionist reinvents himself as the alienist 'Doctor Le Doux, of the Sanitarium, Fairweather Vale, Hampstead' with a 'foreign Diploma (handsomely framed and glazed), of which the doctor had possessed himself by purchase, along with the foreign name'. He asserts that the asylum will always have patients: 'we live in an age when nervous derangement (parent of insanity) is steadily on the increase' ( $7 \mathrm{I} 3$ ). Smoothly charming as he is, Dr Downward is perfectly capable of murder, and conspires with Lydia Gwilt to commit it.

This dark parody of the legitimate doctor also has comments to make about the role of the novelist: when he is asked if his nervous patients are allowed to amuse themselves with novels, he responds:

Only such novels as I have selected and perused myself ... Nothing painful, ma'am! There may be plenty that is painful in real life; but for that very reason, we don't want it in books. The English novelist who enters my house (no foreign novelist will be admitted) must understand his art as the healthy-minded English reader understands it in our time ... All we want of him is - occasionally to make us laugh; and invariably to make us comfortable.

(770)

But of course, this is not how Collins sees his role: he believed that the role of the novelist was not merely to entertain, but to expose abuses and to incite change. In short, the novelist is the truer surgeon, whose job is to expose the hidden and complex reality that ordinary eyes miss; the surgeon's scalpel may be therapeutic, but it rarely 'make[s] us comfortable'. But Collins also warns us about the scientist who sees the emotions and imagination only as subordinate handmaidens to reason. It is novels and intuition that teach the dangers of the world; art that simply confirms or panders to existing prejudices without challenging the reader leaves the reader vulnerable to the quackery of a Dr Downward.

Even good doctors in Armadale unwittingly expose the limits of materialist views. When Ozias Midwinter reports a disturbing dream he believes to be prophetic, Hawbury, a sympathetic surgeon rationalises it. Midwinter retorts 
that, 'The view of a medical man, when he has a problem in humanity to solve, seldom ranges beyond the point of his dissecting-knife.' The doctor responds with a general positivist rule of evidence that natural explanations should always be sought first. He then turns to what readers will recognise as a case study method, drawing out a detailed explanation of the dream from the dreamer's recent experiences, and then framing it in this physiological theory of dreams: 'A dream is the reproduction, in the sleeping state of the brain, of images and impressions produced on it in the waking state; and this reproduction is more or less involved, imperfect, or contradictory, as the action of certain faculties in the dreamer is controlled more or less completely by the influence of sleep' (I73-4). Jenny Bourne Taylor, in her thorough study of Collins's engagement with Victorian psychology, points out that Hawbury's presentation of dream theory represents a selective engagement: he focuses on the impact of recent experience on the individual self, whereas some Victorian psychologists also concerned themselves with the impact of more distant and transindividual past elements on the content of the dream. Collins, she argues, positions Midwinter's self as a palimpsest of recent and distant past experience, including that inherited from his father. He must learn to reinterpret the dream in order to free himself of his nervous, 'hysterical' sensibility in a process that is partly a psychological self-analysis and partly a religious reinterpretation. But, she also notes, the novel foregrounds uncertainty in determining the meaning of mental phenomena: 'Armadale ... is never able to ... reach a final interpretation of the dream, or offer a stable interpretation of itself to the reader. ${ }^{20}$ And, persuasive as the doctor's explanation is, Midwinter the 'mystic' is unconvinced, and the dream in fact does have predictive value, though Midwinter is able to change the doom he thinks the dream portends, giving the lie to his own terror of ineluctable predestination. The doctor here is kindly, but ineffectual, and ultimately incorrect.

Meanwhile, although Armadale contains that necessity of most popular sensation novels, a scheming villainess, Lydia Gwilt shows not even the most equivocal signs of 'nervousness', let alone insanity, until she falls in love. Under that influence, her nerves are affected, but not to madness. Her new sensitivity hampers her ability to commit crime; in effect, it makes her saner than she was before. On the other hand, the text abounds with men on the verge of a nervous breakdown. The tale begins with the first Allan Armadale's narration, from his deathbed, in the grip of nervous paralysis after 'a wild life, and a vicious life' ( I $_{5}$ ) in the West Indies during slavery, and the damage to his nerves wrought by his own murder of a rival. His son, the protagonist Ozias Midwinter, is repeatedly told he must be careful of his nerves as they are apt to fail him. Even his other son, the model of manly English health Allan 
Armadale, possesses a telltale 'nervous antipathy' (I 40): 'a nervous horror of the smell and taste of brandy' (68I).

Further, the nervousness of the men undermines their moral fibre, rather than improving it, as Lydia's does. Old Mr Bashwood, whose crush on Lydia drives him to crime, is repeatedly described as a 'poor broken-down, nervous wretch ... now shrinking in the glare of the lamp, now wincing under the shock of Allan's sturdy voice' (279). His passion for Lydia Gwilt becomes obsession, and her death leaves him insane. Midwinter struggles to do right while consumed by a superstitious fear that he is fated to harm his friend and benefactor Allan. Midwinter's mixed-race ancestry (his mother was of mixed European and African heritage) enhances his tendency to superstition and hysteria, while making him repulsive to the nervous susceptibilities of the more healthy-minded Englishmen of the novel:

If this man was honest, his eyes showed a singular perversity in looking away and denying it. Possibly they were affected in some degree by a nervous restlessness in his organization, which appeared to pervade every fibre in his lean, lithe body. The rector's healthy Anglo-Saxon flesh crept responsively at every casual movement of the usher's [Midwinter's] supple brown fingers, and every passing distortion of the usher's haggard yellow face.

Although Midwinter's nervousness might be accounted for by his lifetime of abuse and hardship, the text repeatedly refers to his ancestry and physiology a combination of his mother's African emotional susceptibility and the inheritance of a constitution vitiated by 'the sins of the father'. When he is angered by his wife's denial of their marriage, 'His eyes began to glitter; and the savage blood that he had inherited from his mother rose dark and slow in his ashy cheeks', but the incident ends, not with his enacting any savage violence, but in a disabling fainting fit (757).

What particularly drives Midwinter to behave 'hysterically' (other than the uncanny experience of repeatedly finding himself in situations anticipated in nightmare, which might well unsettle anyone) is the notion of fate embodied in the figure of modern clockwork that symbolises a mechanistic universe. The Major, a neighbour whose hobby is tending a scale model of the Strasbourg clock, demonstrates its workings. The machinery goes awry, so that although the figure of Time lowers and raises his scythe on cue, doors fail to open properly and so the other figures go through their motions in an untimely, ridiculous manner that elicits a hysterical fit of laughter in the susceptible Midwinter and thus offends the Major and his daughter.

If Midwinter is upset by the machinations of Time the Reaper who inexorably brings fate and death, the failure of the other figures to go properly through their motions (exiting one door, crossing to and entering another) 
foreshadows the climactic scene of the long novel, when Lydia depends on perfectly timing a complex set of mechanical actions with the closing and locking of doors to kill her enemy by introducing poisoned air into his room. The suspense of the scene is heightened by the emphasis on the necessity to wait, watching the clock in the asylum, '[a] clock of the noiseless sort incapable of offending irritable nerves' (779), in order to take each of the several actions necessary to accomplish the murder:

Oh, the time! the time! If it could only have been begun and ended with the first Pouring! ... The first of the intervals of five minutes was endless. The time stood still. The suspense was maddening ... The fever-heat throbbed again in her blood, and flushed fiercely in her cheeks. Swift, smooth, and noiseless, she paced from end to end of the corridor, - her eye moment after moment on the clock.

This time, all the machinery works perfectly, even the 'pacing' (a dual meaning here) figure of Lydia. But her husband Midwinter, sensing danger to Allan, has exchanged rooms with her intended victim as a precaution against any attempt on his life. Lydia is able to save Midwinter, and ends by taking her own life as restitution to him for her crimes. The clockwork, materialist view of human actions is again disrupted, this time by the power of imagination and sympathy represented by the warning of the supernatural dream, and the power of love to reform even a hardened evildoer such as Lydia. Human beings, Collins tell us, are not mere physiological mechanisms.

In this novel, doctors are not central to the plot: they are not principal characters, for example, and even Dr Downward holds a relatively small place in the overall length of the novel, as he does not play an important role until the last section. That said, doctors and medicine are vital to the novel's themes and structure: the entire novel is framed in the conflict between what Collins defines as a medico-scientific mode of understanding human experience and an intuitive, 'mystical' one. Moreover, the characters' actions and reactions proceed from a carefully defined physiological basis, even if their capacities ultimately transcend those limitations. Collins is careful to get his facts right about the actions of chemicals and illnesses on the body, and notes in his epilogue that, 'Wherever the story touches on questions connected with Law, Medicine, or Chemistry, it has been submitted before publication to the experience of professional men' $\left(8 \mathrm{I}_{7}\right)$. The final resolution of the epistemological conflict in the favour of the mystical, slyly proffered as a triumph of the novelist's art over a potentially spurious scientism, also reinscribes the value of science - in its place - by having the erroneous spokesperson for science be a quack. The recovery of Midwinter also functions as a kind of medical and artistic triumph, a validation of the organism's ability to 
Sensation fiction and the medical context

regenerate itself under the direction of a human will: 'After causing some anxiety at first to the medical men ... he [Midwinter] has rallied, as only men of his sensitive temperament (to quote the doctors again) can rally' (8I I). The imaginative temperament, finally, is materially stronger than materialism.

\section{NOTES}

I. John Ruskin, 'Fiction Fair and Foul', in The Works of John Ruskin, ed. Edward Tyas Cook and Alexander Wedderburn, 39 vols. (London: George Allen, 1903I2), vol. Xxxiv, 264-399.

2. Lawrence Rothfield, Vital Signs: Medical Realism in Nineteenth-Century Fiction (Princeton University Press), xvii.

3. Raymond Williams, The Country and the City (London: Chatto and Windus, I973).

4. Mansel, 268.

5. Nicholas Daly, Literature, Technology and Modernity: 1860-2000 (Cambridge University Press, 2010), 46.

6. Ibid., 47 , emphasis in original.

7. The National Temperature League and the British Medical Association, Medical Temperature Journal 5-6:57 (I883), 24-34 (31).

8. Tabitha Sparks, The Doctor in the Victorian Novel: Family Practices (Aldershot: Ashgate, 2009), 7-8.

9. Ibid., 8 .

Io. Peter M. Logan, 'Imitations of Insanity and Victorian Medical Aesthetics', Romanticism and Victorianism on the Net 49 (2008), [www.erudit.org/revue/ ravon/2008/v/n 49/OI 7855 ar.html\#re InoI, accessed I 5 January 20I2].

I I. Wilkie Collins, Man and Wife, ed. Norman Page ( Oxford University Press, 2008), 2I8. A further reference to this edition wil be given in the text.

I2. Francis Ainstie, 'State Medicine', Macmillan's Magazine I I:64 (I 864-5), 306-I6 (3I2).

I3. Jill Matus, Unstable Bodies: Victorian Representation of Sexuality and Maternity (Manchester University Press, I995), 202.

I4. Mary Elizabeth Braddon, Lady Audley's Secret, ed. Lyn Pykett (Oxford University Press, 2009), 374. A further reference to this edition will be given in the text.

I 5. Peter M. Logan, Nerves and Narratives: A Culural History of Hysteria in Nineteenth-Century British Prose (Berkeley: University of California Press, I997).

I6. E. Fuller Torrey and Judy Miller, Invisible Plague: The Rise of Mental Illness from I750 to the Present (New Brunswick NJ: Rutgers University Press, 2007), 94.

I7. J. Russell Reynolds, 'An Address on Specialism in Medicine', The Medical Press and Circular (I9 October I88I), 335-8 (337).

I8. Sparks, The Doctor in the Victorian Novel, I3-I4.

I9. Wilkie Collins, Armadale, ed. John Sutherland (Oxford University Press, 2009), $4 \mathrm{IO}$. Further references to this edition will be given in the text.

20. Jenny Bourne Taylor, 'In the Secret Theatre of Home': Wilkie Collins, Sensation Narrative, and Nineteenth-Century Psychology (London: Routledge, I988), I72. 